Research Article

\title{
Comparative Study of Clostridium difficile Clinical Detection Methods in Patients with Diarrhoea
}

\author{
Yanyan Xiao $(\mathbb{D}$, Yong Liu $(\mathbb{D}$, and Xiaosong Qin (iD) \\ Department of Clinical Laboratory, Shengjing Hospital of China Medical University, Shenyang, China \\ Correspondence should be addressed to Xiaosong Qin; qinxs@sj-hospital.org
}

Received 7 September 2019; Accepted 30 November 2019; Published 22 January 2020

Academic Editor: Christian Bautista

Copyright (C) 2020 Yanyan Xiao et al. This is an open access article distributed under the Creative Commons Attribution License, which permits unrestricted use, distribution, and reproduction in any medium, provided the original work is properly cited.

\begin{abstract}
Objectives. The aim of this study was to evaluate the clinical application of three methods for detecting Clostridium difficile in fecal samples. Methods. One hundred and fifty fecal specimens were collected and tested for C. difficile using three methods: (1) the toxigenic culture (TC); (2) the VIDAS enzyme immunoassay (EIA): the VIDAS glutamate dehydrogenase (GDH) assay and toxin $\mathrm{A} / \mathrm{B}$ assay were used to detect GDH antigen and A/B toxin; and (3) the GeneXpert PCR assay. The toxigenic culture was used as a reference to evaluate the performance of the VIDAS EIA and the GeneXpert PCR assay. Results. Of 150 specimens, 26 carried both $\mathrm{A}$ and $\mathrm{B}$ toxin genes, and none of the samples were positive for the binary toxin gene. Toxin-producing C. difficile was found in $17.3 \%$ (26/150) of the samples. Thirty-seven GDH-positive samples were detected using the VIDAS GDH assay, and 15 toxinpositive samples were detected using the VIDAS toxin A/B assay. The GeneXpert PCR assay was used to detect C. difficile in 79 specimens simultaneously, and a total of 18 positive specimens were detected. Conclusion. The VIDAS GDH assay is useful for initial screening of $C$. difficile. The GeneXpert PCR assay is a simple and quick method.
\end{abstract}

\section{Introduction}

Clostridium difficile (CD) is widely distributed in the natural environment and in human and animal feces. It is also a common cause of intestinal infection in hospital patients. $C$. difficile spores are highly resistant to general disinfection measures and can be present in the environment for several months [1]. C. difficile is one of the main causative agents of antibiotic-associated diarrhea (AAD). Diarrhoea occurs as a result of the secretion of $C$. difficile toxin $A$, toxin $B$, and binary toxin. Nontoxigenic $C$. difficile is a nonpathogenic bacterium, belonging to the colonization of bacteria in the body [2]. Recently, a more virulent strain of the bacteria, referred to as restriction endonuclease analysis group BI, North American pulsefield type 1, and PCR ribotype 027 (BI/NAP1/027), has emerged and has been linked to a more severe disease with an increased risk for severe complications and high mortality [3]. In 2012, BI/NAP1/027 was first reported in Beijing, China [4].

The main symptoms of $C$. difficile infection are fever, abdominal pain, diarrhoea, and severe pseudomembranous colitis (PMC). Infection may lead to severe complications such as toxic megacolon and intestinal perforation, which may lead to death [5]. Presently, C. difficile detection is carried out in some areas of China, but the methods used for detection differ between areas. Additionally, routine detection of C. difficile is not carried out in some areas, which is not conducive to rapid detection of the disease. As a result, missed diagnoses and delays in treatment may occur. Currently, no relevant detection data in this area of study have been published. In this study, we evaluated three different $C$. difficile detection methods using fecal specimens from patients with diarrhoea, and the clinical applicability of the three different detection methods was compared. The purpose of this study is to provide a laboratory basis for the diagnosis, treatment, prevention, and control of $C$. difficile infection-related diseases.

\section{Methods}

2.1. Stool Samples. This study was conducted in accordance with the clinical practice guidelines for Clostridium difficile 
infection (CDI) in adults and children updated by the Infectious Diseases Society of America (IDSA) and the Society for Healthcare Epidemiology of America (SHEA) in 2017 [6]. A total of 150 stool specimens were collected from patients over 2 years of age who developed diarrhoea ( 3 or more stools during a 24 hour period) from December 2016 to August 2018 at the Shengjing Hospital of China Medical University. The average age of the patients was 55.3 years, and $44.0 \%(66)$ were males and $56.0 \%(84)$ were females. The C. difficile positive strains (BI/NAP1/027) were donated from the Peking Union Medical College Hospital serving as the positive control of the study.

2.2. Toxigenic Culture (TC). The stool sample was inoculated onto CDIF agar (bioMérieux, France). Simultaneously, a stool specimen $(1.0 \mathrm{~mL})$ was mixed with an equal volume of anhydrous ethanol and incubated for 1 hour at room temperature. Then, the mixed stool sample was inoculated onto anaerobic blood agar (JIZHANG Limited) and CCFA agar (Oxoid Limited). The agars were incubated at $37^{\circ} \mathrm{C}$ for at least 24 hours before final interpretation of the results. When positive culture results were obtained, the isolated $C$. difficile colonies were tested for toxin production using a multiplex PCR-based toxin gene test (BBI Life Science Corporation, 01035, HK).

The multiplex amplification of toxins was performed as described previously [7], and the primers used are shown in Table 1. Bacterial colonies were prepared for PCR as follows: 20-30 colonies were transferred into $200 \mu \mathrm{L}$ of $10.0 \%$ Chelex-100 (Solarbio Ltd) in TE $(10 \mathrm{mM}$ Tris- $\mathrm{HCl}, 1 \mathrm{mM}$ EDTA, $\mathrm{pH}$ 8), boiled for 10 minutes, and then centrifuged briefly. The supernatant was then used for PCR. A 5-plex PCR was developed for the detection of tcdA, tcdB, cdtA, $\mathrm{cdtB}$, and $16 \mathrm{~S} \mathrm{rDNA}$. The PCR reactions were run in total volumes of $50 \mu \mathrm{L}$ containing the following reagents: $27 \mu \mathrm{l}$ Taq PCR Master Mix, $1 \mu \mathrm{l}$ DNA template, $9.5 \mu \mathrm{l}$ PCR water, and $12.5 \mu \mathrm{l}$ primer mixture. The thermocycler conditions were $10 \mathrm{~min}$ at $94^{\circ} \mathrm{C}$, followed by 35 cycles of 50 seconds at $94^{\circ} \mathrm{C}, 40$ seconds at $56^{\circ} \mathrm{C}$, and 50 seconds at $72^{\circ} \mathrm{C}$, and a final step of 3 minutes at $72^{\circ} \mathrm{C}$.

2.3. Enzyme Immunoassays (EIA). All specimens were tested simultaneously for GDH (Glutamate dehydrogenase, a conserved antigen which is abundantly present on the surface of both toxigenic and nontoxigenic strains of $C$. difficile) and $\mathrm{A} / \mathrm{B}$ toxins using commercial VIDAS kits (bioMérieux, Marcy-l'Étoile, France) according to manufacturer's instructions. For the GDH assay, a negative result was defined as optical density (OD) $450 / 630 \mathrm{~nm}<0.10$, and a positive result was defined as OD $450 / 630 \mathrm{~nm} \geq 0.10$. The fluorescence intensities for $\mathrm{A} / \mathrm{B}$ toxin of $<0.13, \geq 0.13$ to $<0.37$, and $\geq 0.37$ were considered negative, equivocal, and positive, respectively.

2.4. The GeneXpert C. difficile PCR Assay. The GeneXpert $C$. difficile PCR assay, a real-time PCR assay, was carried out in accordance with the manufacturer's instructions. The specimen was vortexed at high speed for 15 seconds, and a sterile dry swab was then dipped into the stool for testing. The excess stool was removed, and the swab was placed into a vial containing the sample reagent. The swab's stem was then broken off after lifting it a few $\mathrm{mm}$, so that the cap could be closed tightly. The vial was then vortexed at high speed for 10 seconds. All the liquid from the sample was transferred into the "S" chamber of the cartridge using a large transfer pipette (Cepheid), and the chamber was then placed into the GeneXpert Dx System instrument for analysis. The results were determined by the GeneXpert Dx System using measured fluorescence signals and embedded algorithms.

\section{Results}

3.1. Detection of C. difficile Toxin-Positive Strains. In fecal specimens from 150 patients with diarrhea, 26 toxin-positive strains were detected by multiplex PCR, and both A and B toxins were present. No binary toxin-positive strains were found. Overall, $17.33 \%$ of the cases tested were toxin-positive (26/150). Thirty-seven positive samples were detected by the VIDAS GDH assay, and 15 positive samples were detected by the VIDAS toxin A/B assay. Seventy-nine specimens were tested using the GeneXpert $C$. difficile PCR assay, and 18 toxin B-positive cases were detected.

3.2. Comparison of Initial Screening Methods for CDI. To compare the sensitivity and specificity of the CDI detection methods in question, the anaerobic culture method was used as a reference method. First, the clinical application of the VIDAS C. difficile GDH assay was evaluated. Compared with the culture method, the sensitivity, specificity, positive predictive value (PPV), and negative predictive value (NPV) of the VIDAS GDH assay were $100.0 \%, 97.4 \%, 91.9 \%$, and $100.0 \%$, respectively. The sensitivity and NPV of the VIDAS GDH assay were both $100.0 \%$, and consistency analysis revealed that the results of the VIDAS assay and the culture method were highly consistent (Kappa $=0.945)$. A chisquare test showed that there was no statistical difference between the two methods $\left(\chi^{2}=1.33, P>0.05\right)$ (Table 2).

3.3. Comparison of C. difficile Toxin Detection Methods. The toxigenic culture method was next used as a reference to evaluate the clinical application of the GeneXpert C. difficile PCR assay and the VIDAS enzyme immunoassay. The sensitivity, specificity, PPV, and NPV of the GeneXpert $C$. difficile PCR assay were $100.0 \%, 96.8 \%, 88.9 \%$, and $100.0 \%$, respectively, and the sensitivity, specificity, PPV, and NPV of the VIDAS enzyme immunoassay were $55.6 \%, 100.0 \%$, $100.0 \%$, and $88.4 \%$, respectively. The results showed that there was no significant difference between the GeneXpert $C$. difficile PCR assay and the reference method $\left(\chi^{2}=0.50, P>0.05\right)($ Table 3$)$. The results also showed no statistically significant differences between the VIDAS enzyme immunoassay and the reference method $\left(\chi^{2}=3.125, P>0.05\right)$ (Table 4). The diagnostic parameters of the GeneXpert $C$. difficile PCR assay and the VIDAS enzyme immunoassay results are shown in Table 5 . 
TABle 1: Primers used in the present analysis.

\begin{tabular}{|c|c|c|c|c|}
\hline Gene target & Primer name & Sequence $\left(5^{\prime}\right.$ to $\left.3^{\prime}\right)$ & Primer concentration $(\mu \mathrm{M})$ & Amplicon size (bp) \\
\hline $\operatorname{tcd} A$ & tcdA-F3345 & GCATGATAAGGCAACTTCAGTGGTA & 0.6 & 629 \\
\hline $\operatorname{tcdB}$ & $\begin{array}{l}\text { tcdB-F5670 } \\
\text { tcdB-R6079A } \\
\text { tcdB-R6079B }\end{array}$ & $\begin{array}{c}\text { CCAAARTGGAGTGTTACAAACAGGTG } \\
\text { GCATTTCTCCATTCTCAGCAAAGTA } \\
\text { GCATTTCTCCGTTTTCAGCAAAGTA }\end{array}$ & $\begin{array}{l}0.4 \\
0.2 \\
0.2\end{array}$ & 410 \\
\hline $\operatorname{cdt} \mathrm{A}$ & $\begin{array}{l}\text { cdtA-F739A } \\
\text { cdtA-F739B } \\
\text { cdtA-R958 }\end{array}$ & $\begin{array}{l}\text { GGGAAGCACTATATTAAAGCAGAAGC } \\
\text { GGGAAACATTATATTAAAGCAGAAGC } \\
\text { CTGGGTTAGGATTATTTACTGGACCA }\end{array}$ & $\begin{array}{c}0.05 \\
0.05 \\
0.1\end{array}$ & 221 \\
\hline $\operatorname{ctdB}$ & $\begin{array}{l}\text { ctdB-F617 } \\
\text { cdtB-R878 }\end{array}$ & $\begin{array}{l}\text { TTGACCCAAAGTTGATGTCTGATTG } \\
\text { CGGATCTCTTGCTTCAGTCTTTATAG }\end{array}$ & $\begin{array}{l}0.1 \\
0.1\end{array}$ & 262 \\
\hline $16 \mathrm{~S}$ rDNA & $\begin{array}{l}\text { PS13 } \\
\text { PS14 }\end{array}$ & $\begin{array}{l}\text { GGAGGCAGCAGTGGGGAATA } \\
\text { TGACGGGCGGTGTGTACAAG }\end{array}$ & $\begin{array}{l}0.05 \\
0.05\end{array}$ & 1062 \\
\hline
\end{tabular}

TABLE 2: Comparison of the VIDAS C. difficile GDH assay and the anaerobic culture method.

\begin{tabular}{lccc}
\hline The VIDAS GDH assay & \multicolumn{2}{c}{ The anaerobic culture } \\
& Positive & Negative & Total \\
\hline Positive & 34 & 3 & 37 \\
Negative & 0 & 113 & 113 \\
Total & 34 & 116 & 150 \\
\hline
\end{tabular}

TABle 3: Comparison of the GeneXpert C. difficile PCR assay and the toxigenic culture method.

\begin{tabular}{|c|c|c|c|}
\hline \multirow[t]{2}{*}{ The GeneXpert C. difficile PCR assay } & \multicolumn{2}{|c|}{$\begin{array}{l}\text { The toxigenic } \\
\text { culture method }\end{array}$} & \multirow[t]{2}{*}{ Total } \\
\hline & Positive & Negative & \\
\hline Positive & 16 & 2 & 18 \\
\hline Negative & 0 & 61 & 61 \\
\hline Total & 16 & 63 & 79 \\
\hline
\end{tabular}

TABLE 4: Comparison of the VIDAS enzyme immunoassay and the toxigenic culture method.

\begin{tabular}{lccc}
\hline The VIDAS enzyme immunoassay & \multicolumn{3}{c}{ The toxigenic } \\
& $\begin{array}{c}\text { culture method } \\
\text { Positive }\end{array}$ & Negative & Total \\
\hline Positive & 10 & 0 & 10 \\
Negative & 8 & 61 & 69 \\
Total & 18 & 61 & 79 \\
\hline
\end{tabular}

Compared to the reference method, the GeneXpert C. difficile PCR assay has high sensitivity and specificity. The VIDAS enzyme immunoassay has a high specificity $(100.0 \%)$, but the sensitivity is only $55.6 \%$. Consistency analysis showed that the consistency between the GeneXpert assay and the reference method was significantly higher $($ Kappa $=0.925)$ than that of the VIDAS enzyme immunoassay and the reference method (Kappa $=0.659$ ).

The area under the ROC curve of the three methods was compared and statistically tested. The area under the GeneXpert $C$. difficile PCR assay and the VIDAS enzyme
TABLE 5: Diagnostic parameters of laboratory test methods.

\begin{tabular}{lccccc}
\hline Method & Sensitivity & Specificity & PPV & NPV & $\begin{array}{c}\text { Kappa } \\
\text { value }\end{array}$ \\
\hline $\begin{array}{l}\text { The GeneXpert C. } \\
\text { difficile PCR assay }\end{array}$ & 1.000 & 0.968 & 0.889 & 1.000 & 0.925 \\
$\begin{array}{l}\text { The VIDAS } \\
\text { enzyme }\end{array}$ & 0.556 & 1.000 & 1.000 & 0.884 & 0.659 \\
immunoassay & & & & & \\
\hline
\end{tabular}

immunoassay curves were 0.984 and 0.813 , respectively. There was a significant difference between the area under the curve of the VIDAS enzyme immunoassay and the toxigenic culture method $(Z=3.000, P<0.05)$, and there was no significant difference between the area under the curve of the GeneXpert $C$. difficile PCR assay and the toxigenic culture method $(Z=1.426, P>0.05)$. The results are summarized in Table 6 and Figure 1.

\section{Discussion}

C. difficile is a major cause of antibiotic-associated diarrhoea. The methods commonly used for $C$. difficile detection include culture methods, enzyme immunoassays, and molecular biology methods [8]. At the present time, only some areas of China carry out routine detection of $C$. difficile in patient samples. A meta-analysis published in 2016 suggested that the incidence of toxigenic CDI with diarrhoea in China from 2010 to 2016 was $14.0 \%$ [9]. In the same year, another published meta-analysis suggested that the pooled incidence rate of CDI was 19.0\% [10]. In our study, the rate of detection of toxigenic C. difficile was $17.3 \%$, similar to those previously reported.

For the initial screening methods for CDI, the anaerobic culture method is routinely used to detect CDI. However, this method takes 1-3 days to complete, which is not conducive to rapid clinical diagnosis [5]. Additionally, this method cannot distinguish whether the strain is toxigenic or not. The greatest advantage of the GDH enzyme immunoassay is that it has a high sensitivity and NPV [11]. In this study, the performance of the VIDAS GDH assay was evaluated in comparison to the culture method. The results showed that there was no statistically significant difference 
TABLE 6: Comparison of the area under the ROC curve between the toxin detection methods of 79 specimens.

\begin{tabular}{lccc}
\hline Method & $Z$ value & $P$ value & Area under the curve \\
\hline $\begin{array}{l}\text { The toxigenic culture } \\
\text { The GeneXpert } C \text {. difficile PCR assay }\end{array}$ & \multirow{2}{*}{0.426} & 1.000 \\
\hline $\begin{array}{l}\text { The toxigenic culture } \\
\text { The VIDAS enzyme immunoassay }\end{array}$ & \multirow{2}{*}{3.000} & \multirow{2}{*}{0.0027} & 0.984 \\
\hline
\end{tabular}

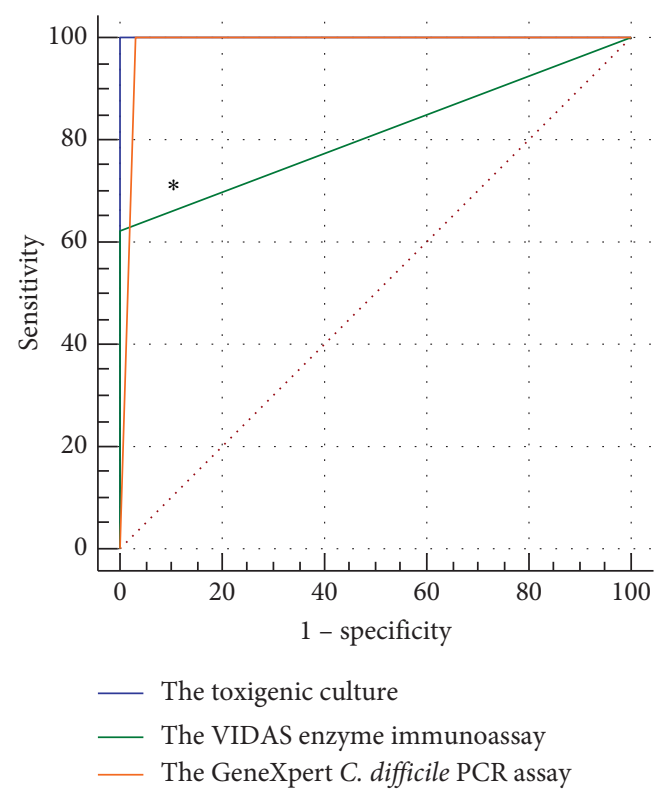

FIGURE 1: The area under the ROC curve of the toxigenic culture, the GeneXpert $C$. difficile PCR assay, and the VIDAS enzyme immunoassay (79 specimens). The area under the GeneXpert $C$. difficile PCR assay and the VIDAS enzyme immunoassay curves were 0.984 and 0.813 , respectively. ${ }^{*}$ Significantly different as compared with the toxigenic culture method $(P<0.05)$.

between the two methods. The sensitivity and NPV of the VIDAS GDH method reached $100.0 \%$, which was consistent with previous reports [12-15]. These results indicate that the VIDAS GDH assay is a reliable initial screening test for CDI, and it may be used as an initial test in two- or three-step algorithms for CDI diagnosis. Therefore, further tests may not be necessary in GDH-negative samples. The VIDAS $\mathrm{GDH}$ assay is quick and relatively inexpensive to perform. However, this method cannot distinguish between toxinpositive and toxin-negative strains [16]. Since the detection of toxins is necessary for CDI diagnosis, this assay cannot be used independently to diagnose CDI.

Toxigenic culture was also used as a reference method to evaluate the performance of the GeneXpert C. difficile PCR assay and the VIDAS enzyme immunoassay. The results showed no statistically significant differences between the GeneXpert $C$. difficile assay and the toxigenic culture method. The results also showed no significant differences between the VIDAS enzyme immunoassay and the toxigenic culture method. The GeneXpert C. difficile PCR assay had high sensitivity and specificity, while the VIDAS enzyme immunoassay had high specificity but low sensitivity. The experimental data show that the sensitivity of the toxin enzyme immunoassay varies greatly (from $40.0 \%$ to $100.0 \%$ ) [17-20] There are a few factors which may contribute to this: first of all, the toxigenic culture method cannot quantitatively detect $C$. difficile. It can only detect whether toxigenic C. difficile is present in the feces. The VIDAS enzyme immunoassay can quantitatively detect $C$. difficile toxin protein, but if the amount of $C$. difficile in the patient sample is less than the lower limit of detection, a false negative result is possible. At the same time, the VIDAS toxin A/B assay is limited by the time of detection. If the specimen is in transit for too long or improperly transported, the toxin proteins in the stool specimen may degrade, which may also lead to false negative results.

The toxigenic culture method is the gold standard for detection of $C$. difficile. However, the cultivation time is long (2-3 days), and it is cumbersome to perform [11,15,21]. The VIDAS enzyme immunoassay is easy to perform, and the results are available in 2-3 hours, but false negative results can occur if the toxin proteins are allowed to degrade. The GeneXpert $C$. difficile assay combines sample purification, nucleic acid amplification, and target sequence determination in simple or complex samples to report results in a short period of time. It is fast, accurate, and easy to use, but it is also very expensive [22].

One limitation of this study is that due to financial reasons, only the first 79 specimens were tested using the GeneXpert C. difficile assay. The sensitivity, specificity, PPV, and NPV of the VIDAS enzyme immunoassay using all 150 specimens were $50.0 \%, 99.2 \%, 92.9 \%$, and $90.4 \%$, respectively. The sensitivity of the VIDAS enzyme immunoassay using 150 specimens was $5.6 \%$ lower than the results obtained when using only the first 79 specimens. However, both results suggest that the VIDAS enzyme immunoassay has low sensitivity. Since only 79 specimens were used to compare the sensitivities, the random sampling error may be inflated. Simultaneously, the small sample size may affect the analysis of other potential clinical differences between patients, such as analysis of risk factors for $C$. difficile infection. In our study, samples were collected for almost 2 years, and the results showed that the prevalence of $C$. difficile infection was consistent with that reported domestically. This may be attributable to a lack of awareness on the part of clinicians concerning the clinical diagnosis of the disease.

Future clinical studies using the GeneXpert PCR assay to detect $C$. difficile should focus on the false positives. A larger sample size should be analyzed, and patient follow-up should occur in order to further evaluate the efficiency of this method.

The prevalence of $C$. difficile may be underestimated because doctors and patients know little about the disease. Therefore, increasing publicity and educating clinicians and 
patients about the disease should be a high priority. The $C$. difficile spores can survive in the environment for several months and can resist high temperatures, oxygen, and disinfectants; this may play a role in the transmission of $C$. difficile [23]. A recently published study examined wards of patients infected with $C$. difficile and concluded that increased sample surface area in the ward was related to increased numbers of recovered spores and increased proportions of positive samples. This study also found that C. difficile contamination was common on hospital railings and floors, especially in the rooms of patients with C. difficile infection [24]. Further studies should focus on the transmission of $C$. difficile, especially in hospital settings.

Presently, no flawless methods of detection for C. difficile exist, and all of the current methods have shortcomings. Future studies should focus on the regulation of spore formation and toxin genes, which may enable development of a new detection method. Discovery and detection of genes that regulate $C$. difficile toxin and spores, combined with the measurement of $C$. difficile toxin and spore gene levels, may enable rapid detection of $C$. difficile. Simultaneously, it may help guide the diagnosis, treatment, and evaluation of $C$. difficile infection after treatment.

In conclusion, the VIDAS GDH assay was found to be useful as an initial screening method due to its excellent sensitivity and NPV. The VIDAS enzyme immunoassays are affected by factors such as detection time, and are therefore more prone to false negative results. The GeneXpert $C$. difficile PCR assay is simple, quick, accurate, and valuable for clinical detection of $C$. difficile.

\section{Data Availability}

The data used to support the findings of this study are included within the article.

\section{Conflicts of Interest}

The authors declare no conflicts of interest.

\section{Acknowledgments}

This work was supported by the Natural Science Foundation of Liaoning (item number: 2015020517) and 345 Talent Project.

\section{References}

[1] K. H. Kim, R. Fekety, D. H. Batts et al., "Isolation of Clostridium difficile from the environment and contacts of patients with antibiotic-associated colitis," Journal of Infectious Diseases, vol. 143, no. 1, pp. 42-50, 1981.

[2] D. E. Voth and J. D. Ballard, "Clostridium difficile toxins: mechanism of action and role in disease," Clinical Microbiology Reviews, vol. 18, no. 2, pp. 247-263, 2005.

[3] M. P. Bauer, D. W. Notermans, B. H. van Benthem et al., "Clostridium difficile infection in Europe: a hospital-based survey," The Lancet, vol. 377, no. 9759, pp. 63-73, 2011.

[4] J.-W. Cheng, M. Xiao, T. Kudinha et al., "The first two Clostridium difficile ribotype 027/ST1 isolates identified in
Beijing, China-an emerging problem or a neglected threat?" Scientific Reports, vol. 6, no. 1, p. 18834, 2016.

[5] C.-A. D. Burnham and K. C. Carroll, "Diagnosis of Clostridium difficile infection: an ongoing conundrum for clinicians and for clinical laboratories," Clinical Microbiology Reviews, vol. 26, no. 3, pp. 604-630, 2013.

[6] L. C. Mcdonald, D. N. Gerding, S. Johnson et al., "Clinical practice guidelines for Clostridium difficile infection in adults and children: 2017 update by the Infectious Diseases Society of America (IDSA) and Society for Healthcare Epidemiology of America (SHEA)," Clinical Infectious Diseases, vol. 66, no. 7, pp. e1-e48, 2018.

[7] S. Persson, M. Torpdahl and, and K. E. P. Olsen, "New multiplex PCR method for the detection of Clostridium difficile toxin $\mathrm{A}(\operatorname{tcd} A)$ and toxin $\mathrm{B}(\mathrm{tcd} B)$ and the binary toxin $(c d t A / c d t B)$ genes applied to a Danish strain collection," Clinical Microbiology and Infection, vol. 14, no. 11, pp. 1057-1064, 2008.

[8] P. H. Gilligan, "Contemporary approaches for the laboratory diagnosis of Clostridium difficile infections," Seminars in Colon and Rectal Surgery, vol. 25, no. 3, pp. 137-142, 2014.

[9] C. Tang, L. Cui, Y. Xu et al., "The incidence and drug resistance of Clostridium difficile infection in Mainland China: a systematic review and meta-analysis," Scientific Reports, vol. 6, no. 1, p. 37865, 2016.

[10] H. B. Xie, H. Zeng, K. Yin, and X. H. Yao, "Prevalence rate of Clostridium difficile infection in hospitalized patients with diarrhoea in China: a meta-analysis," Chinese Journal of Nosocomiology, vol. 27, pp. 961-964, 2017.

[11] S. H. Cohen, D. N. Gerding, S. Johnson et al., "Clinical practice guidelines for Clostridium difficile infection in adults: 2010 update by the Society for Healthcare Epidemiology of America (SHEA) and the Infectious Diseases Society of America (IDSA)," Infection Control \& Hospital Epidemiology, vol. 31, no. 5, pp. 431-455, 2010.

[12] K. A. Davies, C. E. Berry, K. A. Morris et al., "Comparison of the vidas $C$. difficile GDH automated enzyme-linked fluorescence immunoassay (ELFA) with another commercial enzyme immunoassay (EIA) (Quik Chek-60), two selective media, and a PCR assay forgluDfor detection of Clostridium difficile in fecal samples," Journal of Clinical Microbiology, vol. 53, no. 6, pp. 1931-1934, 2015.

[13] J. W. Cheng, M. Xiao, T. Kudinha et al., "The role of glutamate dehydrogenase $(\mathrm{GDH})$ testing assay in the diagnosis of Clostridium difficile infections: a high sensitive screening test and an essential step in the proposed laboratory diagnosis workflow for developing countries like China," PLoS One, vol. 10, no. 12, Article ID e0144604, 2015.

[14] K. Culbreath, E. Ager, R. J. Nemeyer, A. Kerr, and P. H. Gilligan, "Evolution of testing algorithms at a university hospital for detection of Clostridium difficile infections," Journal of Clinical Microbiology, vol. 50, no. 9, pp. 3073-3076, 2012.

[15] B. M. Shin, E. J. Lee, J. W. Moon, and S. Y. Lee, "Evaluation of the VIDAS glutamate dehydrogenase assay for the detection of Clostridium difficile," Anaerobe, vol. 40, pp. 68-72, 2016.

[16] O. Yoldas, M. Altindis, D. Cufali, G. Asik, and R. Kesli, “A diagnostic algorithm for the detection of Clostridium difficileassociated diarrhea," Balkan Medical Journal, vol. 33, no. 1, pp. 80-86, 2016.

[17] K. Eastwood, P. Else, A. Charlett, and M. Wilcox, "Comparison of nine commercially available Clostridium difficile toxin detection assays, a real-time PCR Aasay for Clostridium difficile $t c d B$, and a glutamate dehydrogenase detection assay 
to cytotoxin testing and cytotoxigenic culture methods," Journal of Clinical Microbiology, vol. 47, no. 10, pp. 3211-3217, 2009.

[18] R. Le Guern, S. Herwegh, B. Grandbastien, R. Courcol, and F. Wallet, "Evaluation of a new molecular test, the BD Max Cdiff, for detection of toxigenic Clostridium difficile in fecal samples," Journal of Clinical Microbiology, vol. 50, no. 9, pp. 3089-3090, 2012.

[19] K. C. Chapin, R. A. Dickenson, F. Wu, and S. B. Andrea, "Comparison of five assays for detection of Clostridium difficile toxin," The Journal of Molecular Diagnostics, vol. 13, no. 4, pp. 395-400, 2011.

[20] E. De Jong, A. S. De Jong, C. J. M. Bartels et al., "Clinical and laboratory evaluation of a real-time PCR for Clostridium difficile toxin A and B genes," European Journal of Clinical Microbiology \& Infectious Diseases, vol. 31, no. 9, pp. 22192225, 2012.

[21] L. M. Sloan, B. J. Duresko, D. R. Gustafson, and J. E. Rosenblatt, "Comparison of real-time PCR for detection of the tcdC gene with four toxin immunoassays and culture in diagnosis of Clostridium difficile infection," Journal of Clinical Microbiology, vol. 46, no. 6, pp. 1996-2001, 2008.

[22] Y. M. Murad, J. Perez, R. Nokhbeh et al., "Impact of polymerase chain reaction testing on Clostridium difficile infection rates in an acute health care facility," American Journal of Infection Control, vol. 43, no. 4, pp. 383-386, 2015.

[23] D. J. Weber, W. A. Rutala, M. B. Miller, K. Huslage, and E. Sickbert-Bennett, "Role of hospital surfaces in the transmission of emerging health care-associated pathogens: norovirus, Clostridium difficile, and Acinetobacter species," American Journal of Infection Control, vol. 38, pp. S25-S33, 2010.

[24] K. A. Brown, L. K. Macdougall, K. Valenta et al., "Increased environmental sample area and recovery of Clostridium difficile spores from hospital surfaces by quantitative PCR and enrichment culture," Infection Control \& Hospital Epidemiology, vol. 39, no. 8, pp. 917-923, 2018. 


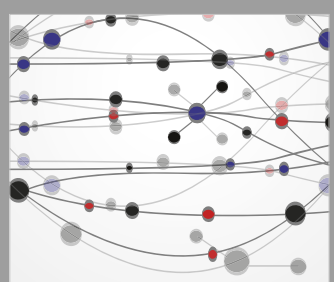

The Scientific World Journal
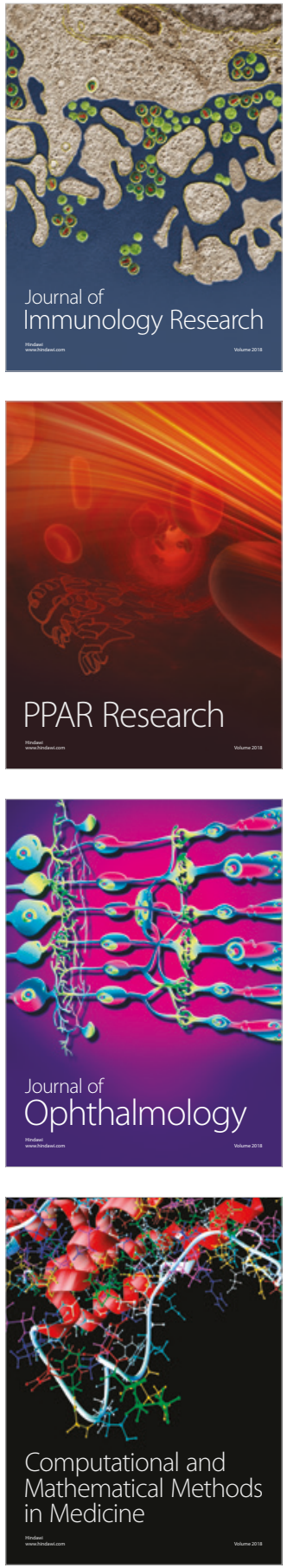

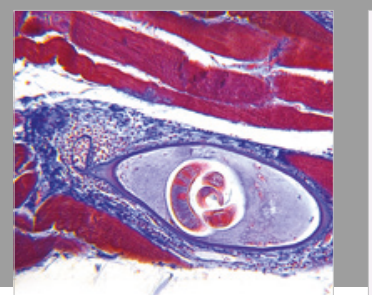

Gastroenterology Research and Practice

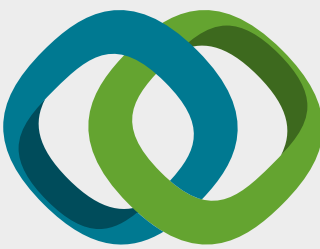

\section{Hindawi}

Submit your manuscripts at

www.hindawi.com
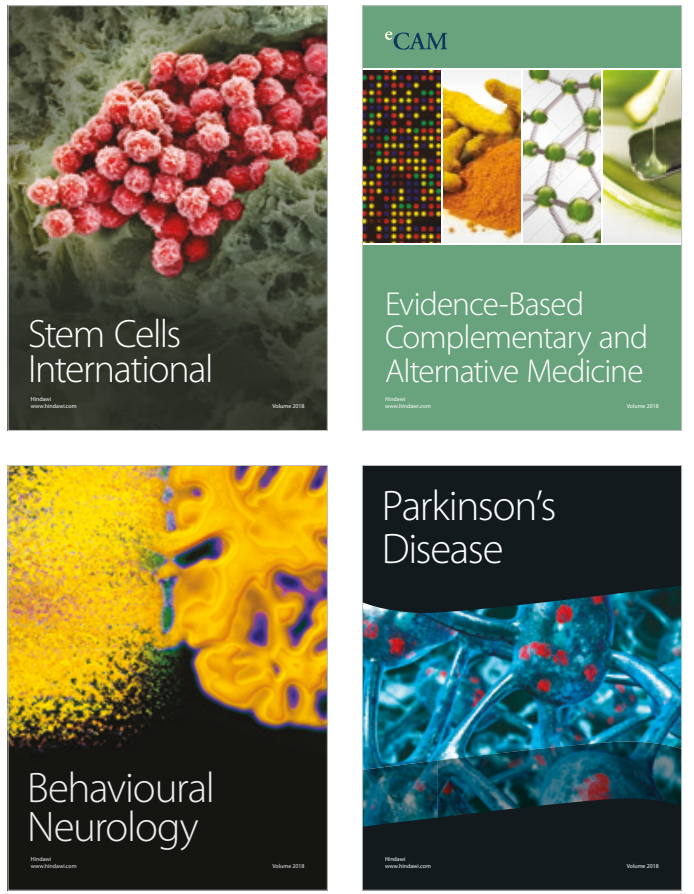

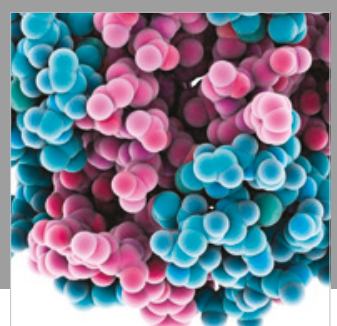

ournal of

Diabetes Research

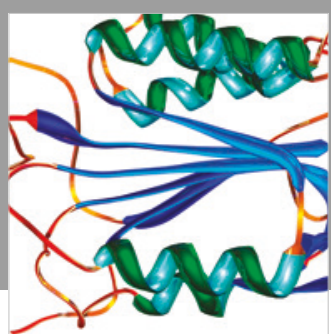

Disease Markers
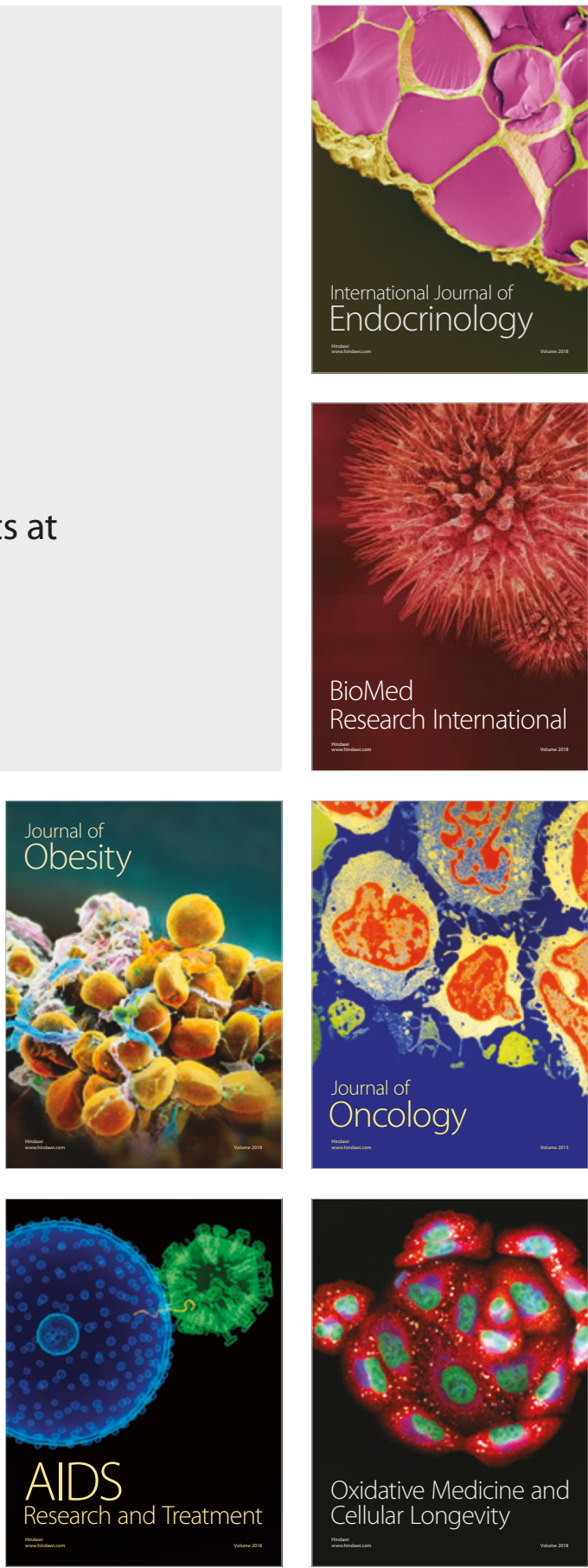